\title{
Short communication: Plasma concentration and tissue mRNA expression of haptoglobin in neonatal calves
}

\author{
H. Sadri, ${ }^{1 *}$ B. Getachew, ${ }^{2}$ M. H. Ghaffari, ${ }^{2}$ H. M. Hammon, ${ }^{3}$ J. Steinhoff-Wagner, ${ }^{3} \dagger$ and H. Sauerwein ${ }^{3} \ddagger$ \\ ${ }^{1}$ Department of Clinical Science, Faculty of Veterinary Medicine, University of Tabriz, 5166616471 Tabriz, Iran \\ ${ }^{2}$ Institute of Animal Science, Physiology and Hygiene Unit, University of Bonn, 53111 Bonn, Germany \\ ${ }^{3}$ Institute of Nutritional Physiology "Oskar Kellner," Leibniz Institute for Farm Animal Biology (FBN), 18196 Dummerstorf, Germany
}

\begin{abstract}
Haptoglobin (Hp), one of the major positive acute phase proteins in cattle, is released in response to proinflammatory cytokines. Colostrum intake might influence the response of the innate immune system, including $H p$ gene expression. Thus, we hypothesized that plasma concentrations and tissue mRNA expression of $\mathrm{Hp}$ in neonatal calves might be influenced by early nutrition in the neonatal calf and would thus be greater if receiving colostrum compared with milkbased formula. Two trials were performed. In trial 1, German Holstein calves were fed either colostrum $(\mathrm{COL} ; \mathrm{n}=7)$ or milk-based formula (FOR; $\mathrm{n}=7$ ) up to $4 \mathrm{~d}$ of life. Blood was sampled from d 1 to 4 before morning feeding and before and $2 \mathrm{~h}$ after feeding on d 4. Tissue samples from liver, kidney fat, duodenum, and ileum were collected after slaughter on d 4 at $2 \mathrm{~h}$ after feeding. In trial 2 , calves born preterm $(\mathrm{n}=7)$ or at term $(\mathrm{n}=7)$ received colostrum only at $24 \mathrm{~h}$ post natum. Blood was sampled at birth, and before and $2 \mathrm{~h}$ after feeding. Tissue samples from liver and kidney fat were collected after slaughter at $26 \mathrm{~h}$ after birth. Blood plasma, colostrum, and formula $\mathrm{Hp}$ concentrations were determined using a competitive ELISA. Tissue expression of $H p$ mRNA was quantified by real-time quantitative PCR. The formula contained much less Hp $(\leq 0.5 \mu \mathrm{g} / \mathrm{mL})$ than colostrum $(69.3,93.9$, and $20.4 \mu \mathrm{g} /$ $\mathrm{mL}$ from $\mathrm{d} 1$ to $\mathrm{d} 3$, respectively). In trial 1, before colostrum or formula feeding, plasma concentrations of $\mathrm{Hp}$ were comparable in both groups. Plasma $\mathrm{Hp}$ increased in FOR after feeding, resulting in greater or a trend for greater plasma Hp concentrations in FOR
\end{abstract}

Received January 18, 2020.

Accepted February 10, 2020.

${ }^{*}$ H. Sadri was a visiting scientist at the Institute of Animal Science, Physiology and Hygiene Unit, University of Bonn, 53115 Bonn, Germany at the time this research was done.

$\dagger$ Present address: Institute of Animal Science, Preventive Health Unit, University of Bonn, 53111 Bonn, Germany.

$\ddagger$ Corresponding author: sauerwein@uni-bonn.de than in COL calves. The mRNA abundance of $H p$ in liver and kidney fat was 3- and 2.2-fold greater in FOR than in COL calves, respectively, whereas duodenal and ileal abundance of $H p$ mRNA did not differ between groups. In trial 2, plasma Hp concentrations decreased slightly over time in term calves, but they did not differ in both groups before and $2 \mathrm{~h}$ after feeding on $\mathrm{d} 2$. The abundance of $H p$ mRNA in liver was 5.3-fold greater in term than in preterm calves, whereas its abundance in kidney fat did not differ between groups. Contrasting our hypothesis, formula, but not colostrum feeding was associated with greater $H p$ mRNA abundance in liver and adipose tissue, indicating that the response of innate immune system seems to be modulated by formula feeding because of the lack of immunoglobulin intake. The lower hepatic abundance of $H p$ mRNA in preterm calves than in term calves may indicate lower synthetic capacity of the liver for $\mathrm{Hp}$ in preterm calves shortly after birth.

Key words: haptoglobin, colostrum, formula, neonatal calf

\section{Short Communication}

The transition from intra- to extrauterine life is associated with dramatic changes in environmental conditions, including exposure to various antigens. The neonate is basically immunocompetent, but the adaptive immune system is immature and innate immunity is not yet fully functional (Fearon and Locksley, 1996). The acute phase response comprises a highly complex sequence of physiological reactions and plays a major role in defense (Cray et al., 2009). The change in circulating concentrations of specific proteins originating mainly in the liver and known as acute-phase proteins (APP) is characteristic of the acute phase response. The APP belong to a large group of biochemically and functionally unrelated proteins whose plasma concentrations increase (positive APP) or decrease (negative APP) several-fold in response to tissue injury, acute infections, burns, or chronic inflammation (Jain et al., 
2011; Tothova et al., 2014; Reczyńska et al., 2018). The exact biological effects of the APP remain partly unknown; in general, they are supposed to participate in innate defense mechanisms and in controlling inflammatory responses to infection, such as binding to foreign substances, having opsonizing activities, and modulating phagocytic cell functions (Gruys et al., 2005; Ceciliani et al., 2012).

The substantial change in the circulating concentration of APP during an acute phase response makes them good candidates for quantifiable indicators of inflammation or infection (Jain et al., 2011; Tothova et al., 2014). Haptoglobin (Hp), one of the major positive APP in cattle (Ceciliani et al., 2012), is a glycoprotein with high hemoglobin binding capacity; it is frequently used in studies evaluating inflammatory conditions in the bovine species. In addition to its numerous other biological functions, Hp is involved in host defense responses to infection and inflammation (Dobryszycka, 1997). Characterization of the changes in APP concentrations after birth may help unravel the role of the inflammatory response in the neonatal adaptation to extrauterine life.

Ensuring adequate colostrum intake is considered the most important factor for calf health and survival because colostrum contains high concentrations of immunoglobulins, antioxidants, and other bioactive factors that support maturation and antioxidative and immune defense, as well as local intestinal immunity (Blum and Hammon, 2000; Chase et al., 2008). Thus, in addition to maturation processes, colostrum intake is also important in acquiring passive immunity because the bovine placenta is impermeable to antibodies. As a consequence, failure of passive transfer is a relevant problem in formula-fed calves. In newborns, the innate immune system is immature, and endogenous production of $\mathrm{Hp}$ is - based on human data - assumed to be low. In contrast to other proteins that are abundant in colostrum, such as IgG, Hp seems not to be transferred into the calf's circulation (Gruse et al., 2016; Liermann et al., 2020). We thus hypothesized that early nutrition of neonatal calves may influence the response of the innate immune system, including Hp gene expression; thus, plasma concentrations and tissue mRNA expression of $\mathrm{Hp}$ will be greater in newborn calves receiving colostrum compared with formula. To test this hypothesis, we used neonatal calves fed either colostrum or formula and compared the time course of the $\mathrm{Hp}$ plasma concentrations and $H p$ mRNA expression in hepatic and extrahepatic tissues during the first $4 \mathrm{~d}$ of life (trial 1). We also hypothesized that the response of the innate immune system, including Hp gene expression, and thus plasma concentrations and tissue mRNA will be divergent in neonatal calves with different matura- tion degrees during the transition to extrauterine life and may react to colostrum feeding. To test this hypothesis, we characterized plasma Hp concentrations and expression of $H p$ mRNA in liver and kidney fat of calves born preterm or at term and receiving colostrum only at $24 \mathrm{~h}$ post natum (trial 2 ).

The experimental procedures performed in trial 1 were in accordance with animal care guidelines and were approved by the relevant authorities of the State Mecklenburg-Vorpommern, Germany (LALLF M-V/ TSD/7221.3-1.1-014/07). The study was performed at the Leibniz Institute for Farm Animal Biology (Dummerstorf, Germany), and calves were kept in single boxes at the Research Station of the University of Rostock, Germany. The calves in the present study were used in a feeding trial to investigate glucose metabolism, as previously described in detail (Steinhoff-Wagner et al., 2011a). Briefly, 14 male German Holstein calves were separated from their dams at birth and transferred to individual, straw-bedded boxes with free access to water. Calves were randomly assigned to 2 experimental groups, each consisting of 7 animals: (1) colostrum (COL), and (2) formula (FOR). Calves were bottlefed either pooled colostrum obtained from d 1, 2, and 3 after parturition or milk-based formula (Bergophor Futtermittelfabrik GmbH, Kulmbach, Germany) with nutrient composition comparable to that of colostrum in the first $3 \mathrm{~d}$ of life. On d 4, calves received either colostrum of d 3 or formula of d 3 in groups COL and FOR, respectively. The daily amount of colostrum or formula fed was targeted to be $8 \%$ of $\mathrm{BW}$ on $\mathrm{d} 1$ and $10 \%$ of $\mathrm{BW}$ on $\mathrm{d} 2$ to 4 . The calves in both groups were slaughtered on d 4 of life, $2 \mathrm{~h}$ after the last feeding. Composition of colostrum and formula milkings are presented in Supplemental Table S1 of Steinhoff-Wagner et al. (2011a). Blood samples were taken from a jugular vein after birth, before the first feeding of colostrum (d 1), from d 2 until d 4 before morning feeding and 2 $\mathrm{h}$ after feed intake on $\mathrm{d} 4$. Tubes containing $\mathrm{K}_{3} \mathrm{EDTA}$ $(1.8 \mathrm{~g} / \mathrm{L}$ blood $)$ were placed on ice and centrifuged at $1,500 \times g$ at $4^{\circ} \mathrm{C}$ for $20 \mathrm{~min}$ to harvest plasma. The plasma was stored at $-20^{\circ} \mathrm{C}$ until analyzed. Calves were stunned by bolt shot and exsanguinated on d 4 of life $2 \mathrm{~h}$ after feeding. Tissue samples from liver, kidney fat, ileum, and duodenum were immediately taken, rinsed with ice-cold saline solution $(0.9 \% \mathrm{NaCl})$, snap-frozen in liquid nitrogen, and stored at $-80^{\circ} \mathrm{C}$ until analyzed.

In trial 2 , the animal ethical and study prerequisites were as described for trial 1 . The calves were used in a study to investigate the maturation of endogenous glucose production in preterm and term calves. Details of this study were reported previously (Steinhoff-Wagner et al., 2011b). Briefly, 14 German Holstein calves, born preterm (PT; 6 male and 1 female) or at term $(\mathbf{T} ; 7$ 
male) were kept in individual boxes with straw bedding and free access to water. Calves in the $\mathrm{T}$ group were spontaneously born after a normal gestation length. Preterm calves were delivered by caesarean section 9 $\mathrm{d}$ before the anticipated calving date. The calves in both groups were slaughtered $26 \mathrm{~h}$ after birth. Because the same calves were being used in studies on glucose metabolism in the fasting state (Steinhoff-Wagner et al., 2011b), they did not receive colostrum in the first $24 \mathrm{~h}$ post natum. Calves were then fed with pooled colostrum from d 3 of lactation at $5 \%$ of BW, 2 h before slaughter. Blood samples were taken from a jugular vein immediately after birth, and before $(24 \mathrm{~h}$ after birth) and $2 \mathrm{~h}$ after final feeding. Preparation of plasma was as described for trial 1. At slaughter, tissue samples from liver and kidney fat were immediately collected, rinsed with ice-cold saline solution $(0.9 \% \mathrm{NaCl})$, snapfrozen in liquid nitrogen, and stored at $-80^{\circ} \mathrm{C}$ until analyzed. Blood plasma, colostrum, and formula were assayed in duplicate for Hp using a bovine-specific ELISA developed in-house, as described elsewhere (Hiss et al., 2009). Colostrum and formula were each assayed at 4 different dilutions to ensure parallelism; expecting low concentrations in the formula, samples were less diluted (between 2- and 5-fold) than the colostrum samples (20- to 400-fold). The serum used as standard had been calibrated against a standard obtained from a European Union Concerted Action on the standardization of animal APP (QLK5-CT-1999-0153; Skinner, 2001). The limit of detection was $0.07 \mu \mathrm{g} / \mathrm{mL}$. The intra- and interassay coefficients of variation $(\mathbf{C V})$ of the assessments in plasma were 3.9 and $12.2 \%$, respectively. For colostrum, the intraassay CV calculated from the mean concentrations of samples with dilutions factored in was $6.6 \%$ (interassay was not assessed due to the low sample number); for formula, the concentrations were low and in the critical range of the standard curve; the intraassay CV calculated accordingly was $15.1 \%$.

Total RNA extraction and cDNA synthesis were conducted as described by Sadri et al. (2017). Quantitative reverse-transcription real-time PCR (qPCR) was performed in an Mx3000P cycler (Stratagene, Amsterdam, the Netherlands) and analyzed in accordance with minimum information for publication of quantitative real-time PCR experiments (MIQE) guidelines (Bustin et al., 2009). The primer sequences and real-time PCR conditions are given in Supplemental Table S1 (https:/ /doi.org/10.3168/jds.2020-18218). Each qPCR reaction was performed in triplicate in a total volume of $10 \mu \mathrm{L}$ comprising $2 \mu \mathrm{L}$ of $\mathrm{cDNA}$ (diluted 1:4) as template, $1 \mu \mathrm{L}$ of the assay-specific primer mix, $5 \mu \mathrm{L}$ of SYBR Green JumpStart Taq Readymix (Sigma-Aldrich, St. Louis, MO), and $2 \mu \mathrm{L}$ of water. For each PCR, a standard curve was generated using serial dilutions of
cDNA to calculate efficiency-corrected relative quantities of the targets (run-specific target amplification efficiency). The target gene $(H p)$ was normalized with the most stable reference genes, which were previously selected according to Saremi et al. (2012b), and their stability was evaluated using qBASEplus version 2.0 (Biogazelle, Ghent, Belgium). The most stable reference genes for each tissue were determined as follows: kidney fat: emerin $(E M D)$, lipoprotein receptor-related protein 10 (LRP10), RNA polymerase II (POLR2A), and ribosomal protein S9 (RPS9); duodenum: RPS9, $\beta$-actin $(A C T B)$, and GAPDH; ileum: RPS9, ACTB, and $G A P D H$; liver: eukaryotic translation initiation factor 3 (EIF3K), hippocalcin-like 1 (HPCAL1), LPR10, and POLR2A.

Plasma data were analyzed using the mixed model of SAS 9.2 (SAS Institute Inc., Cary, NC). The model included group, time, and interaction of group $\times$ time as fixed effects and calf as a random effect. The TukeyKramer adjustment was used to account for multiple comparisons. The threshold of significance was set at $P$ $<0.05$; trends were declared at $0.05 \leq P<0.10$. The mRNA data were analyzed with estimation methods using Mann-Whitney U statistic (Crichton, 2000) and presented as mean difference estimation plots (ClaridgeChang and Assam, 2016). Effect size was measured using Hedges' $g$ (Greenland et al., 2016) as described elsewhere (Sadri et al., 2020) and was referred to as trivial $(g<0.2)$, small $(0.2<g<0.5)$, moderate $(0.5$ $<g<0.8)$, or large $(g>0.8)$, as per standard practice.

The mean concentrations of Hp were much greater in colostrum than in formula, as shown in Table 1. Plasma concentrations of $\mathrm{Hp}$ in $\mathrm{COL}$ and FOR calves from birth to d 4 of life are shown in Figure 1a. Plasma Hp concentrations were affected by treatment $(P=0.01)$, and an interaction of treatment $\times$ time was observed $(P=0.008)$. Before colostrum or formula consumption $(0 \mathrm{~h})$, plasma concentrations of $\mathrm{Hp}$ in both groups were comparable. Plasma Hp concentrations remained unchanged in COL, whereas they increased in FOR after feeding, resulting in greater $(P<0.05$; at $48 \mathrm{~h})$ or a trend for greater $(P<0.10$; at $72 \mathrm{~h})$ plasma Hp concentrations in FOR than in COL. Plasma concentrations of $\mathrm{Hp}$ in COL and FOR calves before and $2 \mathrm{~h}$ after feeding on d 4 of life are shown in Figure 1b. Plasma Hp concentrations were affected by treatment $(P=$ 0.009), being greater in FOR than in COL before and 2 $\mathrm{h}$ after feeding. Plasma Hp concentrations tended $(P=$ $0.09)$ to change over time, and there was no treatment $\times$ time interaction.

Plasma concentrations of $\mathrm{Hp}$ in $\mathrm{PT}$ and $\mathrm{T}$ calves from birth to d 2 of life are shown in Figure 2. The plasma concentrations of $\mathrm{Hp}$ were numerically greater in $\mathrm{T}$ than in PT calves at birth. In $\mathrm{T}$ calves, plasma 
Table 1. Mean haptoglobin (Hp) concentrations in colostrum and formula

\begin{tabular}{lc}
\hline Item & $\mathrm{Hp}(\mu \mathrm{g} / \mathrm{mL})$ \\
\hline Pooled colostrum & \\
d 1 & 69.3 \\
d 2 & 93.9 \\
d 3 & 20.4 \\
Pooled formula & \\
d 1 & $\leq 0.5$ \\
d 2 & $\leq 0.5$ \\
d 3 & $\leq 0.5$ \\
\hline
\end{tabular}
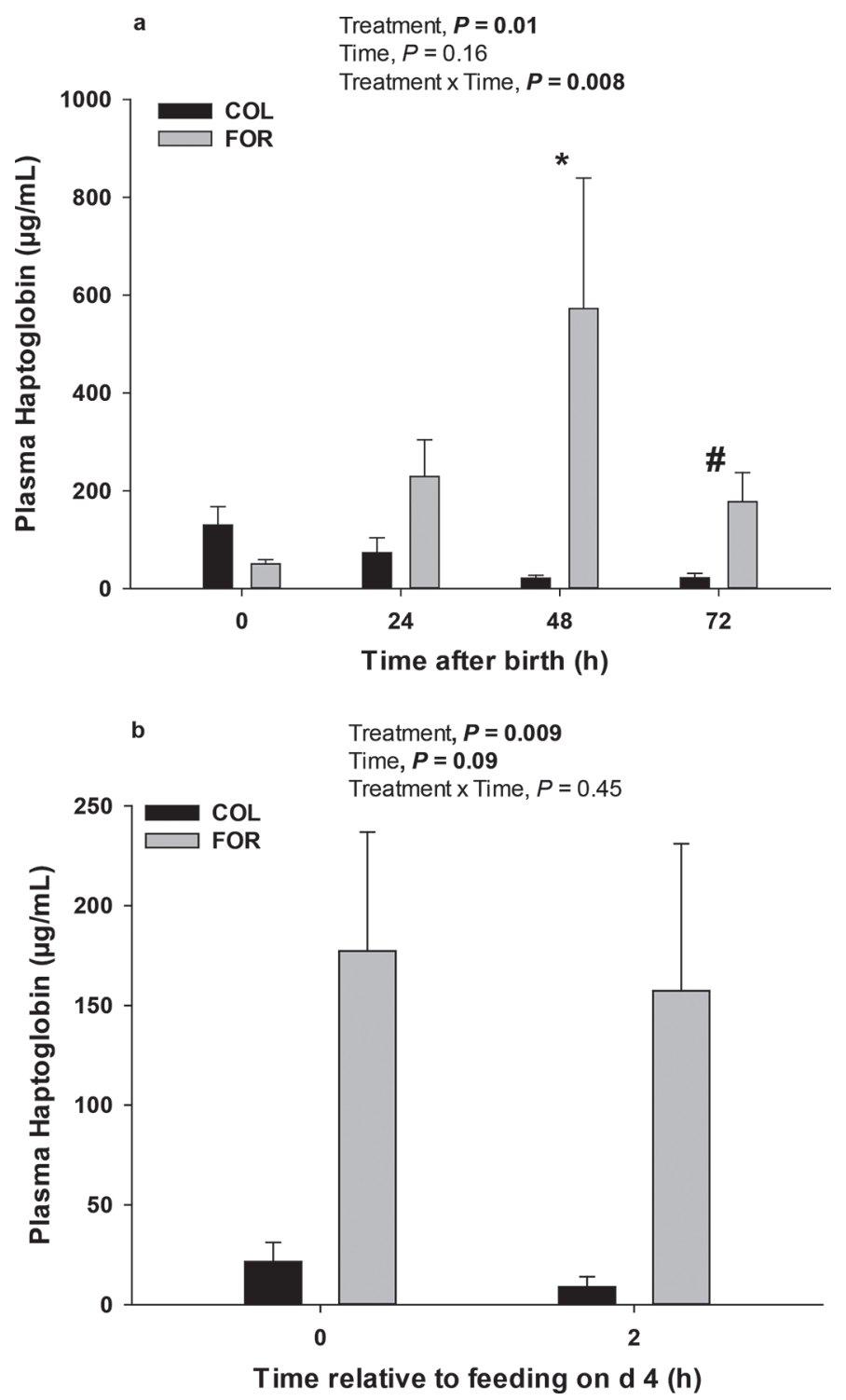

Figure 1. (a) Concentrations of haptoglobin in plasma (means \pm $\mathrm{SEM}$ ) in calves fed either colostrum (COL) or formula (FOR) for $4 \mathrm{~d}$. Symbols indicate a significant difference $\left({ }^{*} P<0.05\right)$ or a trend $(\# P$ $<0.10$ ) between COL and FOR at a given time point. (b) Plasma haptoglobin concentrations of COL- or FOR-fed calves before and $2 \mathrm{~h}$ after feeding on $\mathrm{d} 4$ of life.

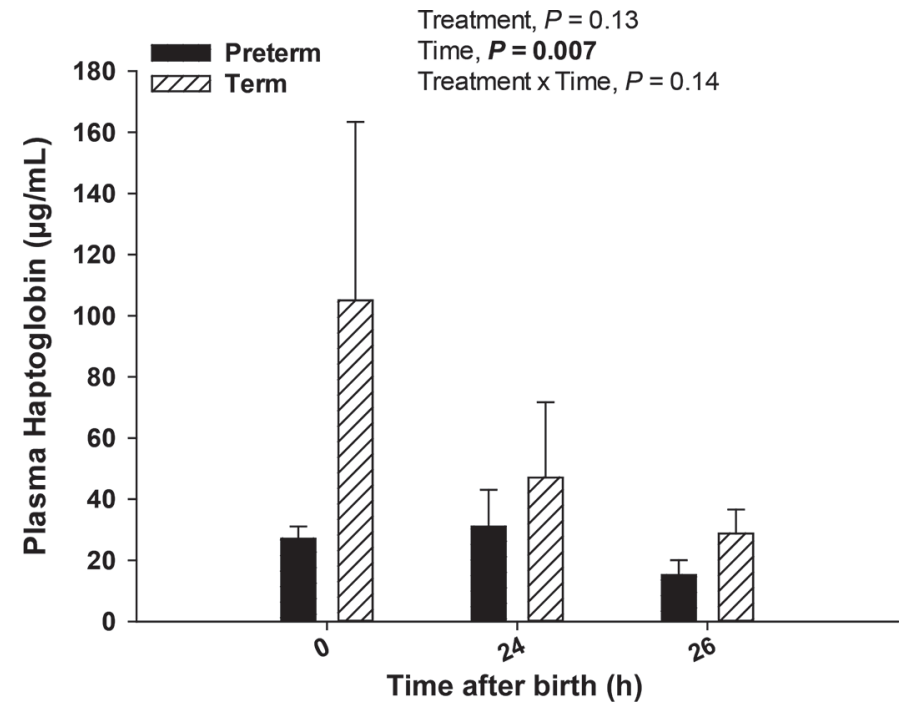

Figure 2. Concentrations of haptoglobin in plasma (means \pm SEM) immediately after birth $(0 \mathrm{~h}), 2 \mathrm{~h}$ before feeding $(24 \mathrm{~h}$ after birth), and $2 \mathrm{~h}$ after final feeding (26 h after birth) in preterm and term-born calves.

Hp concentrations decreased slightly over time $(P=$ 0.007). Plasma Hp concentrations did not differ in $\mathrm{T}$ and PT groups before and $2 \mathrm{~h}$ after feeding on $\mathrm{d} 2$. No treatment $\times$ time interaction was observed for plasma Hp concentrations.

The hepatic mRNA abundance of $H p$ was 3 -fold greater with a large effect size $(g=1.22 ; P=0.03)$ in FOR compared with COL (Figure 3a). The mRNA abundance of $H p$ in kidney fat was 2.2-fold greater with a large effect size $(g=1.22 ; P=0.007)$ in FOR compared with COL (Figure $3 \mathrm{~b}$ ). The mRNA abundance of $\mathrm{Hp}$ in the ileum (Figure 3c) and duodenum (Figure 3d) did not differ between groups. The mRNA abundance of $\mathrm{Hp}$ in liver was 5.3-fold greater with a large effect size $(g=1.16 ; P=0.02)$ in T compared with PT calves (Figure 4a). The abundance of $H p$ mRNA in kidney fat did not differ between groups (Figure 4b,c).

The concentrations of $\mathrm{Hp}$ were 40 to 180 times higher in the colostrum than in the formula. However, we did not pursue further decreasing the assay dilutions; thus, the concentrations reported for formula correspond to the limit of detection at the sample dilutions used. In the present study, we hypothesized that plasma concentrations and tissue mRNA expression of $H p$ will be greater in newborn calves fed colostrum compared with formula. However, in contrast to our hypothesis, feeding formula, but not colostrum, was associated with greater plasma Hp concentrations in neonatal calves, indicating that the response of the innate immune system is modulated by formula feeding. Our results are in contrast to the study of Hiss-Pesch et al. (2011), who reported a 
a

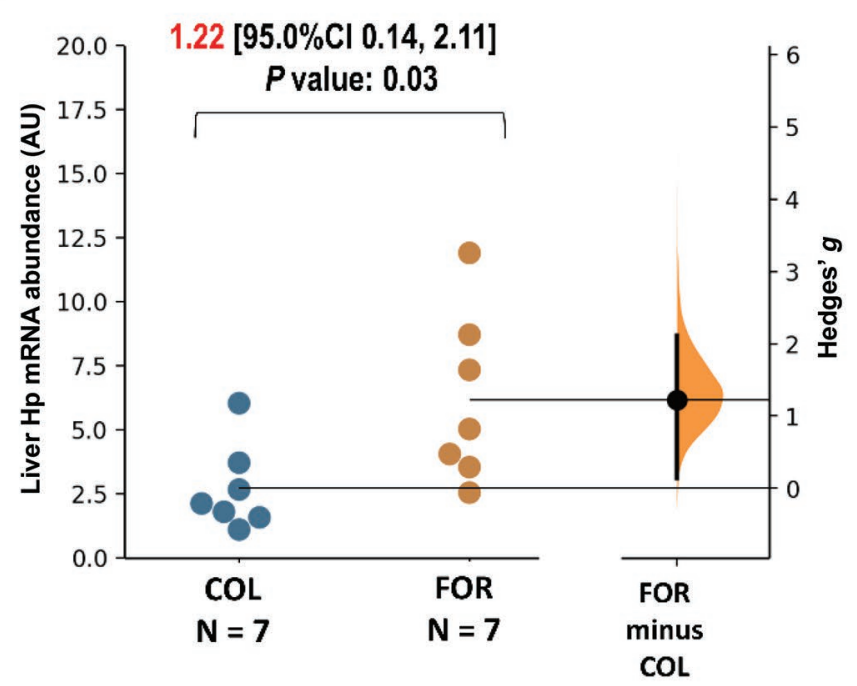

C

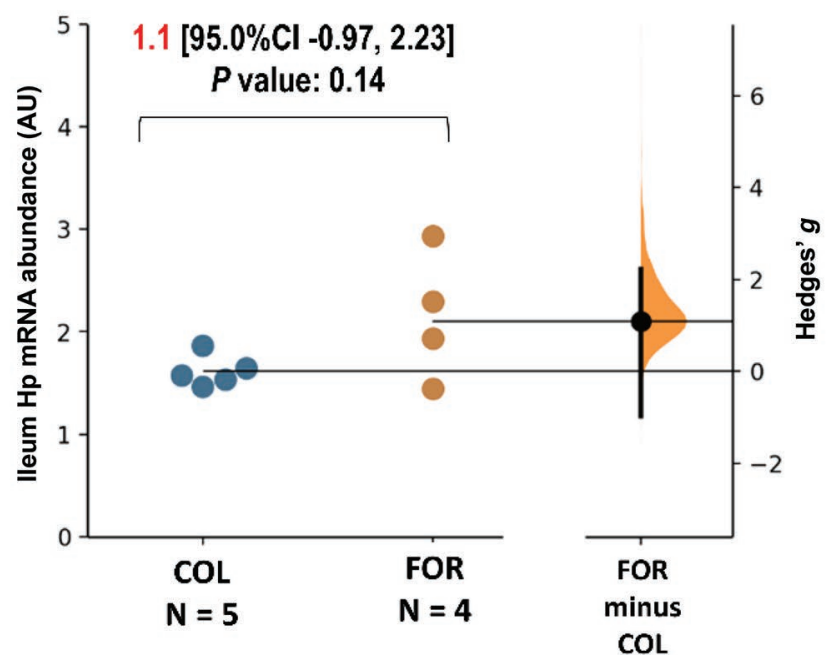

b

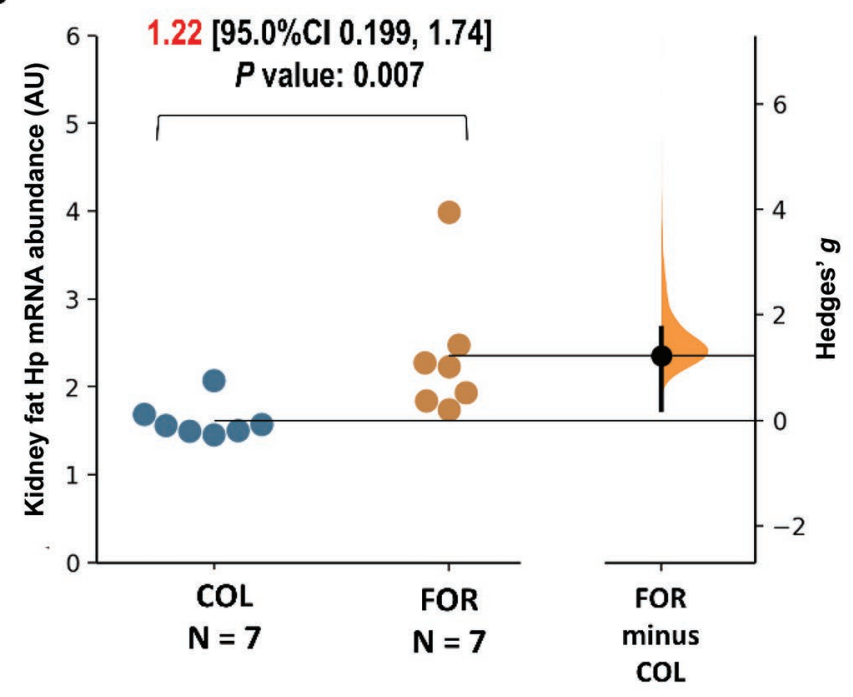

d

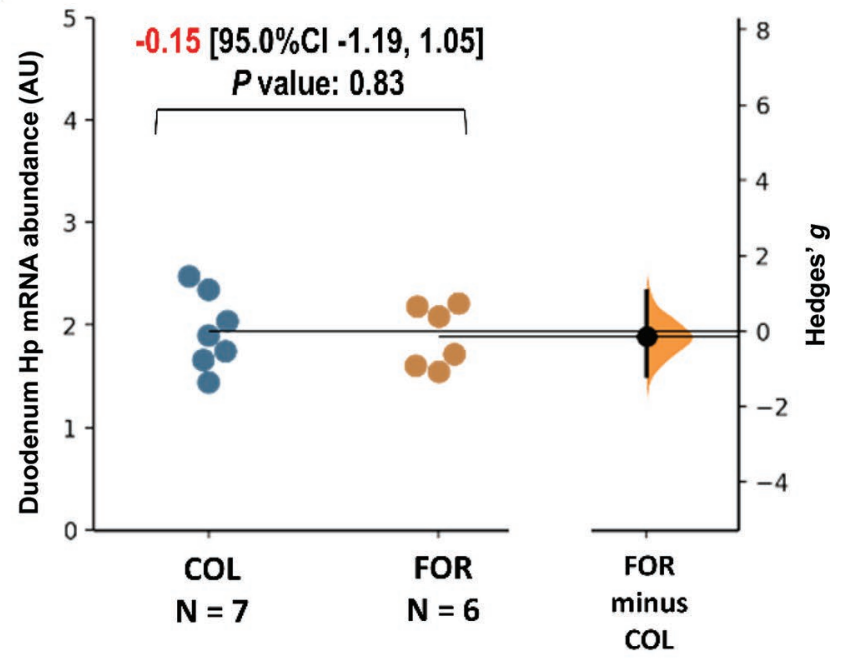

Figure 3. The mRNA abundance of haptoglobin $(H p)$ in liver (a), kidney fat (b), ileum (c), and duodenum (d) of calves fed colostrum $(\mathrm{COL})$ or formula (FOR). The Hedges' $g$ (effect size) between COL and FOR is shown in the Gardner-Altman estimation plot. Both groups are plotted on the left axes; the mean difference is plotted on a floating axis on the right as a bootstrap sampling distribution. The mean difference is depicted as a dot; the $95 \%$ confidence interval is indicated by the ends of the vertical error bar.

direct relationship of increasing circulating Hp concentrations and colostrum consumption after birth in the newborn pigs. They found that serum concentrations of Hp in neonatal piglets were low at birth, but increased substantially during the first $12 \mathrm{~h}$ of life after colostrum intake, whereas no such increase was observed in the colostrum-deprived group receiving an $\mathrm{Hp}$-free milk replacer. Based on these results, Hiss-Pesch et al. (2011) concluded that maternal Hp is transferred from the sow to newborn pigs via colostrum and that the onset of endogenous Hp synthesis in newborn piglets is stimulated by colostrum. However, in the current study, there was no indication of $\mathrm{Hp}$ absorption after the first colostrum intake in neonatal calves. In support of this, Tothova et al. (2011) and Liermann et al. (2020) did not observe direct transfer of $\mathrm{Hp}$ from colostrum to newborn calves. Tothova et al. (2011) suggested that this may be related to the different regulation of $\mathrm{Hp}$ production in the liver between newborn calves and pigs. Similar to our observations, Gruse et al. (2016) reported that formula but not colostrum feeding led to an increase in postnatal plasma Hp concentrations. However, results on $\mathrm{Hp}$ in neonatal calves fed colostrum or formula are conflicting. In a recent study with the same feeding model as in our study, a trend was observed for elevated plasma Hp in colostrum-fed calves (Liermann 
a

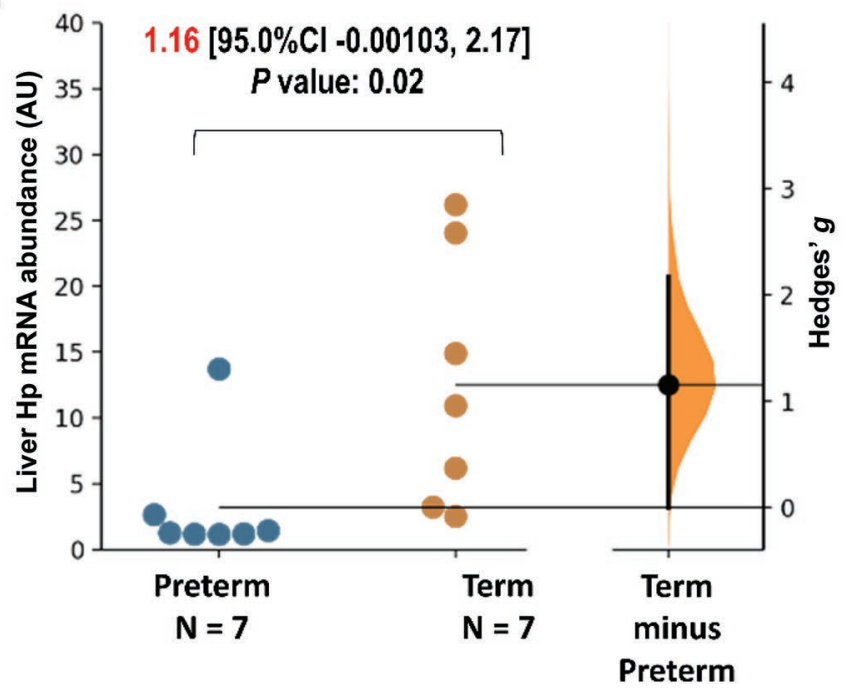

b

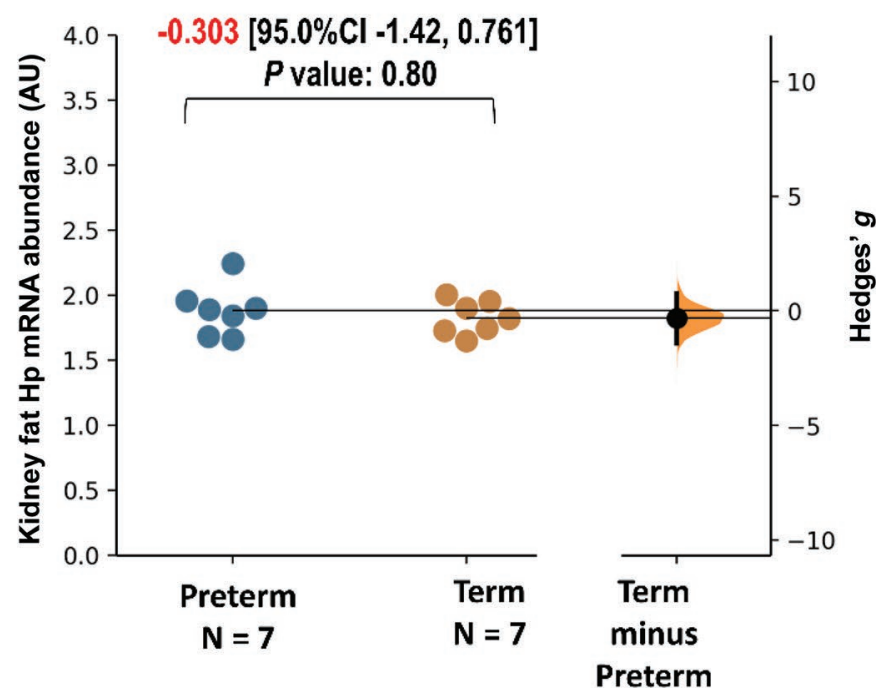

Figure 4. The mRNA abundance of haptoglobin $(H p)$ in liver (a), and kidney fat (b) of preterm or term-born calves. The Hedges' $g$ (effect size) between term and preterm groups is shown in the Gardner-Altman estimation plot. Both groups are plotted on the left axes; the mean difference is plotted on a floating axis on the right as a bootstrap sampling distribution. The mean difference is depicted as a dot; the $95 \%$ confidence interval is indicated by the ends of the vertical error bar.

et al., 2020). The reason for this discrepancy is not clear; however, it is speculated that the higher plasma concentrations of $\mathrm{Hp}$ in formula-fed calves may suggest more severe inflammatory processes than in colostrumfed calves (Besser et al., 1988; Gånheim et al., 2007). Interestingly, activation of the local immune response in the intestinal mucosa was reduced after colostrum feeding compared with formula feeding in a comparable feeding model as used in the present study (Norrman et al., 2003). These findings are supported by the greater incidence of gastrointestinal infections in formula-fed calves (Gruse et al., 2016). It seems that colostrumfed calves have the ability to withstand infections and other factors by exploiting passively transferred immunity against specific pathogens, which results in a low concentration of $\mathrm{Hp}$ in the plasma of these calves. It is also likely that the formula used in the current study contained some substances that were potentially immunogenic in neonates and caused an immune response; this warrants further investigation.

Haptoglobin is mainly produced in the liver, but extrahepatic expression of $H p$ such as in the mammary gland, leukocytes, forestomach, abomasum, and adipose tissue has been reported in cattle (Thielen et al., 2005, 2007; Dilda et al., 2012; Saremi et al., 2012a). In the current study, besides liver and kidney fat, $\mathrm{Hp}$ mRNA was detected in duodenum, and ileum, pointing to local production of APP in the digestive tract and the small intestine being an extrahepatic source of $\mathrm{Hp}$ in neonatal calves. As expected, $H p$ mRNA was detected predominantly in liver compared with other tissues in the current study, confirming that the liver is the main site of Hp synthesis in cattle (Ceciliani et al., 2012). The greater $H p$ mRNA abundance observed in liver and in adipose tissue of the FOR group compared with the COL group in the present study is in line with the plasma data. This finding also supports the hypothesis that the response of the innate immune system might have been accelerated by formula feeding, probably due to lack of maternal (colostral) immunoglobulin intake and some potential immunogenic substances. Formula-fed calves that have no maternal or colostral immunoglobulins may have to invest more in their innate immune response, as is also seen for the local immune response in the ileum (Norrman et al., 2003), and may also show a greater inflammatory response accompanied by elevated synthesis of APP.

In the present study, Hp concentrations were detectable from birth in both $\mathrm{PT}$ and $\mathrm{T}$ calves, being much greater in $\mathrm{T}$ than in $\mathrm{PT}$ calves. However, the variation within the $\mathrm{T}$ group was large; thus, the difference between groups did not reach statistical significance. The greater hepatic abundance of $H p$ mRNA observed in $\mathrm{T}$ calves than in PT calves in the current study followed the direction of change observed for the plasma data. The plasma concentrations and hepatic mRNA abundance of $H p$ may point to a lower hepatic capacity for Hp synthesis in PT calves shortly after birth. Another reason might be related to the way of delivery: cesarean section, as was used for PT calves, is known 
to lack various stimuli for the newborn compared with vaginal birth. In addition to the immunological effects of labor by itself, the exposure to microbes and thus gut colonization is altered (Francino, 2018), and this may have resulted in less stimulation of $\mathrm{Hp}$ secretion in PT calves. Our data in trial 1 showed that intake of colostrum or formula, as an external factor, played an important role causing or exacerbating changes in circulating $\mathrm{Hp}$ of newborn calves. Calves in both PT and $\mathrm{T}$ groups received pooled colostrum from $\mathrm{d} 3$ of lactation only $2 \mathrm{~h}$ before the last blood sampling at $26 \mathrm{~h}$ of life. In view of gut closure occurring around $24 \mathrm{~h}$ post natum and the apparent lack of Hp absorption after colostrum intake in neonatal calves (Tothova et al., 2011), the finding of Hp plasma concentrations being unchanged by the late colostrum feeding was expected. The decrease from birth to $24 \mathrm{~h}$ and $26 \mathrm{~h}$ after birth (on average; before feeding: 47.1/105.1; 2 h after feeding: 28.8/105.1) that was limited to the $\mathrm{T}$ calves, is in line with reports about a decrease of serum $\mathrm{Hp}$ from d 1 (median time from birth $18 \mathrm{~h}$ ) to $\mathrm{d} 3$ of life in dairy calves (Orro et al., 2008). We observed a similar trend of decrease from d 0 to $2(73 / 129)$ and d $3(21 / 129)$ in the colostrum-fed calves in trial 1 . Thus, elevated concentrations of $\mathrm{Hp}$ at birth, followed by a gradual decrease during the first 2 to $3 \mathrm{~d}$ of life, might be associated with the birth process and not necessarily with disease-related processes. Such changes underscore the importance of considering the age of the calf when interpreting APP concentrations in circulation or using them as disease markers (Orro et al., 2008).

In conclusion, formula but not colostrum feeding seemed to stimulate $H p$ mRNA expression in liver and adipose tissue, which was accompanied by greater plasma Hp in FOR calves compared with COL calves at 48 and $72 \mathrm{~h}$ after birth. These data indicate that the response of the innate immune system might be accelerated by formula feeding due to lack of immunoglobulin intake. The plasma concentrations of $\mathrm{Hp}$ were measurable from birth in PT calves, but with a lower hepatic abundance of $H p$ mRNA compared with T calves, which may indicate lower hepatic capacity for Hp synthesis in PT calves shortly after birth. Although our study was not initially designed to characterize long-term changes of $\mathrm{Hp}$ in neonatal calves, these observations should aid in the design of additional studies including other APP with a longitudinal follow-up.

\section{ACKNOWLEDGMENTS}

The authors thank J. Aschenbrenner from Bergophor Futtermittelfabrik GmbH (Kulmbach, Germany) for donation of the formula and A. Zeyner (University of Rostock, Germany) for providing the animal facility.
The authors also express their appreciation to Birgit Mielenz, Isabella Israel, and Inga Hofs (Institute of Animal Science, Physiology and Hygiene Unit, University of Bonn, Germany) for their excellent laboratory assistance. The financial support by Deutsche Forschungsgemeinschaft (DFG, Bonn, Germany) is also gratefully acknowledged (HA 4372/5-1). The authors have not stated any conflicts of interest.

\section{REFERENCES}

Besser, T. E., T. McGuire, C. Gay, and L. Pritchett. 1988. Transfer of functional immunoglobulin $\mathrm{G}$ (IgG) antibody into the gastrointestinal tract accounts for IgG clearance in calves. J. Virol. 62:22342237. https://doi.org/10.1128/JVI.62.7.2234-2237.1988.

Blum, J. W., and H. Hammon. 2000. Colostrum effects on the gastrointestinal tract, and on nutritional, endocrine and metabolic parameters in neonatal calves. Livest. Prod. Sci. 66:151-159. https: //doi.org/10.1016/S0301-6226(00)00222-0.

Bustin, S. A., V. Benes, J. A. Garson, J. Hellemans, J. Huggett, M. Kubista, R. Mueller, T. Nolan, M. W. Pfaffl, G. L. Shipley, J. Vandesompele, and C. T. Wittwer. 2009. The MIQE guidelinesMinimum information for publication of quantitative real-time PCR experiments. Clin. Chem. 55:611-622. https://doi.org/10 .1373/clinchem.2008.112797.

Ceciliani, F., J. J. Ceron, P. D. Eckersall, and H. Sauerwein. 2012. Acute phase proteins in ruminants. J. Proteomics 75:4207-4231. https://doi.org/10.1016/j.jprot.2012.04.004.

Chase, C. C., D. J. Hurley, and A. J. Reber. 2008. Neonatal immune development in the calf and its impact on vaccine response. Vet. Clin. North Am. Food Anim. Pract. 24:87-104. https://doi.org/10 .1016/j.cvfa.2007.11.001.

Claridge-Chang, A., and P. N. Assam. 2016. Estimation statistics should replace significance testing. Nat. Methods 13:108-109.

Cray, C., J. Zaias, and N. H. Altman. 2009. Acute phase response in animals: A review. Comp. Med. 59:517-526.

Crichton, N. 2000. Information point: Mann-Whitney test. J. Clin. Nurs. 9:583.

Dilda, F., L. F. Pisani, M. M. Rahman, S. Modina, I. Tessaro, P. Sartorelli, F. Ceciliani, and C. Lecchi. 2012. Distribution of acute phase proteins in the bovine forestomachs and abomasum. Vet. J. 192:101-105. https://doi.org/10.1016/j.tvjl.2011.05.005.

Dobryszycka, W. 1997. Biological functions of haptoglobin-New pieces to an old puzzle. Eur. J. Clin. Chem. Clin. Biochem. 35:647-654.

Fearon, D. T., and R. M. Locksley. 1996. Elements of immunityThe instructive role of innate immunity in the acquired immune response. Science 272:50-53. https://doi.org/10.1126/science.272 .5258 .50 .

Francino, M. P. 2018. Birth mode-related differences in gut microbiota colonization and immune system development. Ann. Nutr. Metab. 73(Suppl. 3):12-16. https://doi.org/10.1159/000490842.

Gånheim, C., S. Alenius, and K. Persson Waller. 2007. Acute phase proteins as indicators of calf herd health. Vet. J. 173:645-651. https://doi.org/10.1016/j.tvjl.2006.01.011.

Greenland, S., S. J. Senn, K. J. Rothman, J. B. Carlin, C. Poole, S. N. Goodman, and D. G. Altman. 2016. Statistical tests, P values, confidence intervals, and power: A guide to misinterpretations. Eur. J. Epidemiol. 31:337-350. https://doi.org/10.1007/s10654 -016-0149-3.

Gruse, J., E. Kanitz, J. M. Weitzel, A. Tuchscherer, T. Stefaniak, P. Jawor, S. Wolffram, and H. M. Hammon. 2016. Quercetin feeding in newborn dairy calves cannot compensate colostrum deprivation: Study on metabolic, antioxidative and inflammatory traits. PLoS One 11:e0146932. https://doi.org/10.1371/journal.pone.0146932.

Gruys, E., M. J. Toussaint, T. A. Niewold, and S. J. Koopmans. 2005. Acute phase reaction and acute phase proteins. J. Zhejiang Univ. Sci. B 6:1045-1056. https://doi.org/10.1631/jzus.2005.B1045. 
Hiss, S., C. Weinkauf, S. Hachenberg, and H. Sauerwein. 2009. Short communication: Relationship between metabolic status and the milk concentrations of haptoglobin and lactoferrin in dairy cows during early lactation. J. Dairy Sci. 92:4439-4443. https://doi.org/ 10.3168/jds.2008-1632.

Hiss-Pesch, S., F. Daniel, S. Dunkelberg-Denk, M. Mielenz, and H. Sauerwein. 2011. Transfer of maternal haptoglobin to suckling piglets. Vet. Immunol. Immunopathol. 144:104-110. https://doi.org/ 10.1016/j.vetimm.2011.07.015.

Jain, S., V. Gautam, and S. Naseem. 2011. Acute-phase proteins: As diagnostic tool. J. Pharm. Bioallied Sci. 3:118-127. https://doi .org/10.4103/0975-7406.76489.

Liermann, W., C. T. Schäff, J. Gruse, M. Derno, J. M. Weitzel, E. Kanitz, W. Otten, A. Hoeflich, T. Stefaniak, H. Sauerwein, R. M. Bruckmaier, J. J. Gross, and H. M. Hammon. 2020. Effects of colostrum instead of formula feeding for the first two days post natum on whole body energy metabolism and its endocrine control in neonatal calves. J. Dairy Sci. 103:3577-3598. https://doi.org/10 $.3168 /$ jds.2019-17708.

Norrman, J., C. W. David, S. N. Sauter, H. M. Hammon, and J. W. Blum. 2003. Effects of dexamethasone on lymphoid tissue in the gut and thymus of neonatal calves fed with colostrum or milk replacer. J. Anim. Sci. 81:2322-2332. https://doi.org/10.2527/2003 $.8192322 \mathrm{x}$.

Orro, T., S. Jacobsen, J. P. LePage, T. Niewold, S. Alasuutari, and T. Soveri. 2008. Temporal changes in serum concentrations of acute phase proteins in newborn dairy calves. Vet. J. 176:182-187. https: //doi.org/10.1016/j.tvjl.2007.02.010.

Reczyńska, D., M. Zalewska, M. Czopowicz, J. Kaba, L. Zwierzchowski, and E. Bagnicka. 2018. Acute phase protein levels as an auxiliary tool in diagnosing viral diseases in ruminants-A review. Viruses 10:502. https://doi.org/10.3390/v10090502.

Sadri, H., M. H. Ghaffari, K. Schuh, G. Dusel, C. Koch, C. Prehn, J. Adamski, and H. Sauerwein. 2020. Metabolome profiling in skeletal muscle to characterize metabolic alterations of overconditioned cows during the periparturient period. J. Dairy Sci. 103:3730-3744. https://doi.org/10.3168/jds.2019-17566.

Sadri, H., J. Steinhoff-Wagner, H. M. Hammon, R. M. Bruckmaier, S. Görs, and H. Sauerwein. 2017. mTOR signaling and ubiquitin proteasome-related gene expression in three different skeletal muscles of colostrum versus formula fed calves. J. Dairy Sci. 100:9428-9441.
Saremi, B., A. Al-Dawood, S. Winand, U. Müller, J. Pappritz, D von Soosten, J. Rehage, S. Dänicke, S. Häussler, M. Mielenz, and H. Sauerwein. 2012a. Bovine haptoglobin as an adipokine: Serum concentrations and tissue expression in dairy cows receiving a conjugated linoleic acids supplement throughout lactation. Vet. Immunol. Immunopathol. 146:201-211.

Saremi, B., H. Sauerwein, S. Dänicke, and M. Mielenz. 2012b. Technical note: Identification of reference genes for gene expression studies in different bovine tissues focusing on different fat depots. J. Dairy Sci. 95:3131-3138. https://doi.org/10.3168/jds.2011-4803.

Skinner, J. G. 2001. International standardization of acute phase proteins. Vet. Clin. Pathol. 30:2-7. https://doi.org/10.1111/j.1939 -165X.2001.tb00248.x.

Steinhoff-Wagner, J., S. Görs, P. Junghans, R. M. Bruckmaier, E. Kanitz, C. C. Metges, and H. M. Hammon. 2011a. Intestinal glucose absorption but not endogenous glucose production differs between colostrum- and formula-fed neonatal calves. J. Nutr. 141:4855. https://doi.org/10.3945/jn.110.128652.

Steinhoff-Wagner, J., S. Görs, P. Junghans, R. M. Bruckmaier, E. Kanitz, C. C. Metges, and H. M. Hammon. 2011b. Maturation of endogenous glucose production in preterm and term calves. J. Dairy Sci. 94:5111-5123. https://doi.org/10.3168/jds.2011-4355.

Thielen, M. A., M. Mielenz, S. Hiss, and H. Sauerwein. 2005. Qualitative detection of haptoglobin mRNA in bovine and human blood leukocytes and bovine milk somatic cells. Vet. Med. Czech. 50:515520 .

Thielen, M. A., M. Mielenz, S. Hiss, H. Zerbe, W. Petzl, H. J. Schuberth, H. M. Seyfert, and H. Sauerwein. 2007. Short communication: cellular localization of haptoglobin mRNA in the experimentally infected bovine mammary gland. J. Dairy Sci. 90:12151219. https://doi.org/10.3168/jds.S0022-0302(07)71609-0.

Tothova, C., O. Nagy, and G. Kovac. 2014. Acute phase proteins and their use in the diagnosis of diseases in ruminants: A review. Vet. Med. Czech. 59:163-180. https://doi.org/10.17221/7478 -VETMED.

Tothova, C., O. Nagy, H. Seidel, and G. Kovac. 2011. Age-related changes in the concentrations of acute phase proteins and some variables of protein metabolism in calves. Wien. Tierarztl. Monatsschr. 98:33-40. 